\title{
Contrast- Induced Nephropathy after Coronary Angiography
}

\author{
Jawad Ibrahim Rasheed ${ }^{1}$, Manal Khudder Abdul Razak ${ }^{2}$, Ahmed Ghaleb Mahdi ${ }^{3}$ \\ ${ }^{1}$ FRCP, Ph. D, Council of Arab Board of Health Specializations, Baghdad Teaching Hospital, Medical City Complex, Baghdad, Iraq \\ ${ }^{2}$ FRCP, Ph. D Scholar, School of Medicine, Department of Medicine, University of Baghdad, Baghdad, Iraq \\ ${ }^{3}$ Ph. D, Baghdad Teaching Hospital, Medical City Complex, Baghdad, Iraq
}

\begin{abstract}
Contrast induced nephropathy (CIN) has become the third leading cause of hospital-acquired acute kidney injury. We aimed to measure the incidence of (CIN) and to assess predicting major risk factors. We enrolled 302 patients who were admitted to cardiology department of Baghdad Teaching Hospital, for elective catheterization. After taking informed consents, data were collected including (hypertension, diabetes mellitus, use of nephrotoxic drugs). We excluded patients with severe renal dysfunction. Serum creatinine (S. Cr) was obtained before procedure and 48-hour later, only 104 patients completed the study. Our results showed that the incidence of (CIN) was $28.8 \%$ based on a $25 \%$ relative increase in (S. Cr) criteria, $11.5 \%$ based on a 0.5 mg/dL absolute increase in (S. Cr). The incidence was $20 \%$ in patient without risk factors while in those with risk factors was $31.6 \%$. There was a significant relationship between volume of contrast \& (CIN). The functional stage of kidney significantly affects (CIN) and risk was increased in those with prior history of hypertension and nephrotoxic drugs usage. In conclusion, (CIN) was significantly associated with underlying renal dysfunction, history of hypertension, and nephrotoxic drugs usage and volume of contrast was one of the strongest predictors.
\end{abstract}

Keywords: Contrast Induced Nephropathy, Coronary angiography

\section{Introduction}

\section{Epidemiology}

Contrast-induced nephropathy (CIN) or contrast-induced acute kidney injury (CIAKI) is a well-recognized complication of radiological interventions, cardiac catheterization, or invasive procedures that require iodinated contrast administration, where there is a decrease in glomerular filtration rate (GFR) following the injection of these contrast media (CM). It is the third most common cause of in-hospital acute renal failure $(12 \%)$ after decreased renal perfusion $(42 \%)$ and post-operative acute renal failure $(18 \%){ }^{(1)}$

The increasing number of diagnostic and interventional procedures requiring $(\mathrm{CM})$, estimated 75 million doses yearly, makes a higher incidence of $\mathrm{CIN}^{(2)}$. Reported incidence of CIN is $11 \%$ following outpatient computed tomography ${ }^{(3)}, 9 \%$ after peripheral angiography ${ }^{(4)}$, and $4 \%$ after intravenous pyelography ${ }^{(5)}$. When the vast majority of CIN cases still develop after standard radiologic examinations, this complication may also be increasingly encountered after percutaneous coronary interventions (PCI) due to growing numbers of procedures, multiple comorbidities in patients undergoing PCI and larger amounts of CM used for complex coronary lesions.

The incidence of CIN in normal subject ranges from $3.3 \%$ to $8 \%{ }^{(6)}$ and increases to 12 to $20 \%$ for those with renal insufficiency or diabetes mellitus. ${ }^{(7)}$

Functionally, CIN is considered an intrinsic acute kidney injury (AKI), usually with conserved diuresis, but in severe cases acute tubular necrosis and even end-stage renal disease may develop. As acute renal failure is associated with disabling morbidity and mortality, ${ }^{(8)}$ prevention and early detection of CIN are of greater clinical relevance. ${ }^{(9,10)}$

\section{Definition}

CIN is defined as the acute deterioration of renal function after parenteral CM exposure in the absence of other causes. Levels of (S. Cr) usually begin to rise within 24-48 hours of $\mathrm{CM}$ exposure, peaking at 2-3 days and returning to baseline values within 2 weeks ${ }^{(11)}$. CIN is usually defined as a rise in $\mathrm{S}$. $\mathrm{Cr}$ of $\geq 0.5 \mathrm{mg} / \mathrm{dL}(44 \mathrm{mmol} / \mathrm{L})$ or $\geq 25 \%$ increase from baseline assessed within 48 hours after a radiological procedure $^{(12)}$.

\section{Contrast media}

(CM) are all organic iodinated compound, classified into ionic or non-ionic, and into high- osmolar, low- osmolar and iso- osmolar. It is considered that osmolality per se contributes to the reported difference in CIN incidence ${ }^{(6)}$.

\section{Renal handling of contrast media}

After intravenous administration, CM are free-formed molecule and filtered by glomerulus. As the filtrate proceeds along tubule, water is reabsorbed, resulting in concentration 50 to 100 times to plasma ${ }^{(13)}$. $\mathrm{CM}$ in the tubular lumen reduces water reabsorption, leading to an increase in intraluminal pressure and a decrease in the gradient of filtration. This increase in sodium and water delivery to the distal tubule activates the "tubuloglomerular feedback" (TGF) mechanism that reduces the glomerular filtration rate (GFR). The rising of renal interstitial pressure may contribute to the reduced GFR ${ }^{(14)}$ and probably to renal medullary hypoxia by local compression of vasa recta ${ }^{(15)}$.

\section{Pathophysiology of renal iodine toxicity}

At least five mechanisms could contribute to the pathogenesis. 1-Direct toxicity. ${ }^{(15)}$ 2-CM-induced alteration 


\section{International Journal of Science and Research (IJSR) \\ ISSN (Online): 2319-7064}

Index Copernicus Value (2015): 78.96 Impact Factor (2015): 6.391

in renal microvascular. (15) 3 - Reperfusion and reactive oxygen species toxicity. ${ }^{(16)} 4$ - Toxicity due to CM mediated complement cascade activation and inflammatory cytokine release. ${ }^{(16)} 5$ - Toxicity due to tubular obstruction. ${ }^{(15,16)}$ The risk is decreased with new generation CM and hydration ${ }^{(15)}$. Therefore, the osmolarity as well as the viscosity and ionic properties of $\mathrm{CM}$ are involved in nephrotoxicity.

\section{Risk factor of CIN}

Important risk factors are pre-existing renal insufficiency and diabetes mellitus. However, osmolarity and volume of contrast media, reduction of effective intravascular volume and concurrent use of nephrotoxic agents also are independent risk factor for CIN ${ }^{(17)}$. Advancing age is reported to predispose to renal sodium and water wasting due to reduction in renal mass, function, and perfusion. Anemia may be a risk factor for CIN in patient undergoing percutaneous coronary intervention. ${ }^{(18)}$

Adequate risk assessment prior to procedure offers a greater opportunity to prevent CIN. In the absence of effective therapeutic measures for CIN and greater cost and associated morbidity prevention remains the best option. CIN risk scoring could be used to predict the outcome after contrast injection and help in increasing awareness as well as initiate preventive measures.

\section{Aims}

We aimed to determine the incidence of (CIN) in a sample of Iraqi patients who were candidate for coronary angiography and/or angioplasty, and to assess major risk factors predicting the appearance of CIN following these procedures.

\section{Methods}

\section{Study design}

This was an observational prospective single center study conducted in Baghdad Teaching Hospital.

\section{Study sample.}

We enrolled 302 patients who were admitted to cardiology department/ catheterization unit as candidates for coronary angiography and or angioplasty between June 2015 and March 2016. Informed consent was obtained from all patients. A questionnaire was completed for every patient including age, gender, history of hypertension history of diabetes mellitus, and concurrent nephrotoxic drug use (NSAIDs). Renal function was categorized according to the stages set by the National Kidney Foundation, with (eGFR) > $90 \mathrm{ml} / \mathrm{min} / 1.73 \mathrm{~m}^{2}$ as normal, $60-89 \mathrm{ml} / \mathrm{min} / 1.73 \mathrm{~m}^{2}$ as mildly impaired, $30-59 \mathrm{ml} / \mathrm{min} / 1.73 \mathrm{~m}^{2}$ as moderately impaired. Those with $(\mathrm{eGFR})<30 \mathrm{ml} / \mathrm{min} / 1.73 \mathrm{~m}^{2}$ were excluded from the study.

\section{Measurements}

Patient, disease, and procedural data were recorded prospectively, and a careful history and examination were done to assess comorbid conditions, previous exposure to contrast media and drugs, and hydration status. Procedural variables were also recorded, including the type of procedure (diagnostic, interventional), contrast medium type, contrast dye load, and contrast agent.

All patients were electively subjected to catheterization and screened with PHILIPS ALLURA XPER FD 20/10 SYSTEM and receive non- ionic low-osmolar contrast medium IOHEXOL (OMNIPAQUETM ${ }^{\circledR} ; 350 \mathrm{mg} \mathrm{I} \mathrm{/ml;} \mathrm{GE}$ Healthcare Ireland) with variable amount of contrast according to procedure type.

Serum creatinine was obtained for each patient before procedure and 48-hour post procedure. At baseline (eGFR) was calculated. Level of hematocrit was measured. The type and amount of the contrast medium were recorded. The number of patients that complete the study was 104 patients only (those who repeat serum creatinine level measurement after 48 hours), those were included in the study.

\section{Definitions}

- Hypertension: In population aged $\geq 60$ years, systolic blood pressure $(\mathrm{SBP}) \geq 150 \mathrm{~mm} \mathrm{Hg}$ or diastolic blood pressure $(\mathrm{DBP}) \geq 90 \mathrm{~mm} \mathrm{Hg}$ and in population $<60$ years, $\mathrm{SBP} \geq 140 \mathrm{~mm} \mathrm{Hg}$ and at $\mathrm{DBP} \geq 90 \mathrm{~mm} \mathrm{Hg}$. ${ }^{(19)}$

- Diabetes: HBA1C $\geq 6.5 \%$ or Fasting Plasma Glucose $\geq$ $126 \mathrm{mg} / \mathrm{dL}(7.0 \mathrm{mmol} / \mathrm{L})$ or Two-hour plasma glucose $\geq$ $200 \mathrm{mg} / \mathrm{dL}(11.1 \mathrm{mmol} / \mathrm{L})$ during an Oral Glucose Tolerance Test confirmed by repeat testing, or in a patient with classic symptoms of hyperglycemia or hyperglycemic crisis, a random plasma glucose $\geq 200$ $\mathrm{mg} / \mathrm{dL}(11.1 \mathrm{mmol} / \mathrm{L}))$. ${ }^{(20)}$

- Anemia in chronic kidney disease: hemoglobin < $120 \mathrm{~g} / \mathrm{l}$ in women and $<130 \mathrm{~g} / \mathrm{l}$ in men. ${ }^{(21)}$

- Estimated glomerular filtration rate (eGFR) was calculated by Modification of Diet in Renal Disease equation, as follows eGFR $\left(\mathrm{ml} / \mathrm{min} / 1.73 \mathrm{~m}^{2}\right)=\{186.3 \times \mathrm{S}$ $\left.\mathrm{Cr}(\mathrm{mg} / \mathrm{dl}){ }^{1.154}\right\} \times\left\{\right.$ age $\left.^{-0.203}\right\} \times\{0.742\}$ if female. $^{(22)}$

\section{Statistical methods}

The results were reported as the means \pm standard deviation for the quantitative variables and percentages for the categorical variables. Anderson Darling test of normality were perfumed to assess normality of continuous variables; those followed normal distribution independent $t$ test were used to analyzed the mean between 2 groups, while 2 way ANOVA (repeated measure design) used for analyzing 2 separate groups at 2 different intervals. Discrete variables analyzed using chi square test, and data presented using number and percentage. Univariate binary regression used to see the correlation and the odd ratio for each possible risk factor. Two tailed $\mathrm{p}$ value were used and 0.05 (level of significance) were chosen and variables less than 0.05 were statistically significant. All data were analyzed using SPSS20 Microsoft package, and Microsoft Excel used to draw the fingers

\section{Results}

\section{Demographic data}

As shown in table 1, the overall mean age of all patients was $56.64 \pm 9.32$ year, for those how completed the study (104 patients) mean age was $59.31 \pm 9.9$ which is significantly 


\section{International Journal of Science and Research (IJSR) \\ ISSN (Online): 2319-7064}

Index Copernicus Value (2015): 78.96 | Impact Factor (2015): 6.391

higher than those how did not complete the study (198 patients) $55.23 \pm 8.7$ year.

Male gender was the predominant $(72.5 \% ; 219$ patients) in all patients, in those who completed the study males were also the majority ( $75 \% ; 78$ patients).

Table 1: Demographic data of the study sample

\begin{tabular}{|c|c|c|c|c|c|c|}
\hline \multicolumn{3}{|c|}{ Variables } & $\begin{array}{c}\text { Total } \\
\text { number }\end{array}$ & $\begin{array}{c}\text { Not } \\
\text { completed }\end{array}$ & Completed & \begin{tabular}{|c|}
$P$ \\
value
\end{tabular} \\
\hline \multirow{4}{*}{ Gender } & Femple & Number & 83 & 57 & 26 & \multirow{4}{*}{0.501} \\
\hline & Tential & $\%$ & $27.50 \%$ & $28.80 \%$ & $25.00 \%$ & \\
\hline & \multirow{2}{*}{ Male } & Number & 219 & 141 & 78 & \\
\hline & & $\%$ & $72.50 \%$ & $71.20 \%$ & $75.00 \%$ & \\
\hline \multicolumn{2}{|c|}{ Age/ year } & \begin{tabular}{|c|} 
Mean \pm \\
SD $^{*}$
\end{tabular} & $\begin{array}{c}56.64 \pm \\
9.32\end{array}$ & $55.23 \pm 8.7$ & $59.31 \pm 9.9$ & 0.001 \\
\hline \multicolumn{2}{|c|}{ Total number } & \multicolumn{2}{|c|}{302} & 198 & 104 & - \\
\hline
\end{tabular}

\author{
"Standard deviation.
}

As shown in table 2, the distribution of risk factors as well as $\mathrm{S}$. Cr level at baseline between patients who completed the study and those who did not was similar and non-significant differences exist between them.

Table 2: Comparison of risk actors between patients who completed the study and those who did not

\begin{tabular}{|c|c|c|c|c|c|}
\hline \multicolumn{2}{|c|}{ Variables } & \multirow{3}{*}{\begin{tabular}{|c|} 
Total number \\
150 \\
152 \\
\end{tabular}} & \multirow{2}{*}{$\begin{array}{c}\begin{array}{c}\text { Not completed } \\
\text { Number }(\%)\end{array} \\
97(49.0 \%)\end{array}$} & \multirow{2}{*}{$\begin{array}{c}\begin{array}{c}\text { Completed } \\
\text { Number }(\%)\end{array} \\
43(41.3 \%) \\
\end{array}$} & \multirow{2}{*}{$\begin{array}{l}\text { P. value } \\
0.226\end{array}$} \\
\hline \multirow[t]{2}{*}{ HTN $^{*}$} & No HTN & & & & \\
\hline & HTN & & $101(51.0 \%)$ & $61(58.7 \%)$ & \\
\hline \multirow[t]{2}{*}{$\mathrm{DM}^{* *}$} & No DM & 178 & $115(58.1 \%)$ & $63(60.6 \%)$ & \multirow[t]{2}{*}{0.713} \\
\hline & DM & 124 & $83(41.9 \%)$ & $41(39.4 \%)$ & \\
\hline \multirow{2}{*}{$\begin{array}{c}\text { History of nephrotoxic } \\
\text { drugs }\end{array}$} & Negative & 270 & $182(91.9 \%)$ & $88(84.6 \%)$ & \multirow[t]{2}{*}{0.75} \\
\hline & Positive & 32 & $16(8.1 \%)$ & $16(15.4 \%)$ & \\
\hline \multirow[t]{2}{*}{ Anemia } & No anemia & 289 & $190(96.0 \%)$ & $99(95.2 \%)$ & \multirow[t]{2}{*}{0.771} \\
\hline & Anemia & 13 & $8(4.0 \%)$ & $5(4.8 \%)$ & \\
\hline \multirow{3}{*}{$\begin{array}{c}\text { Renal Function stage } \\
\left(\mathrm{eGFR}^{\infty} /\right. \\
\left.\mathrm{ml} / \mathrm{min} / 1.73 \mathrm{~m}^{2}\right)\end{array}$} & $>60$ & 270 & $176(88.9 \%)$ & $94(90.4 \%)$ & \multirow[t]{3}{*}{0.256} \\
\hline & $45-60$ & 27 & $17(8.6 \%)$ & $10(9.6 \%)$ & \\
\hline & $30-44$ & 5 & $5(2.5 \%)$ & $0(0.0 \%)$ & \\
\hline \multicolumn{2}{|c|}{ Baseline Creatinine Level } & Mean $\pm \mathrm{SD}^{* * * *}$ & $0.89 \pm 0.26$ & $0.86 \pm 0.23$ & 0.276 \\
\hline \multicolumn{2}{|c|}{ Total number } & 302 & 198 & 104 & - \\
\hline
\end{tabular}

${ }^{*}$ Hypertension, ${ }^{* *}$ Diabetes mellitus, ${ }^{* * *}$ Standard deviation, ${ }^{\infty}$ Estimated Glomerular Filtration Rate

\section{Contrast induced nephropathy.}

As shown in table 3, CIN was found in 12 out of 104 patients with a rate of $11.5 \%$ according to the first criteria $(0.5 \mathrm{mg} / \mathrm{dl}$ increase) and it was found in 30 patients with rate of $28.8 \%$ according to the second criteria ( $25 \%$ increases).

To see whether the presence of any risk factor in patients (or more than one) affect the rate of CIN; no significant association was found even if we use each criterion for diagnosing CIN, as shown in table 3.
Table 3: The rate of contrast induced nephropathy (CIN) in 104 patients according to risk factor(s). Chi square test was used

\begin{tabular}{|c|c|c|c|c|c|}
\hline Criteria & \multicolumn{2}{|c|}{ No CIN } & \multicolumn{2}{|c|}{ CIN } & \multirow{2}{*}{ P. value } \\
\hline $\begin{array}{c}0.5 \mathrm{mg} / \mathrm{dl} \\
\text { change } \\
\text { criteria }\end{array}$ & \multicolumn{2}{|c|}{$92(88.5 \%)$} & \multicolumn{2}{|c}{$12(11.5 \%)$} & \\
\cline { 2 - 5 } & No risk & No. $(\%)$ & $23(92.0)$ & $2(8.0)$ & 0.525 \\
\cline { 2 - 5 } $\begin{array}{c}25 \% \text { change } \\
\text { criteria }\end{array}$ & $74(71.2 \%)$ & \multicolumn{2}{|c|}{$30(28.8 \%)$} & \\
\cline { 2 - 5 } & No risk & No. (\%) & $20(80.0)$ & $5(20.0)$ & 0.263 \\
\cline { 2 - 5 } & Risk & No. (\%) & $54(68.4)$ & $25(31.6)$ & \\
\hline
\end{tabular}

As shown in table 4,5 ; there was a statistically significant association between functional stage of kidney, type of procedure and volume of $\mathrm{CM}$ and development of CIN. Anemia was not found to be a significant risk factor for CIN.

Table 4: Cross tabulation of different risk factors versus CIN using $0.5 \mathrm{mg} / \mathrm{dl}$ change as role.

\begin{tabular}{|c|c|c|c|c|c|c|}
\hline \multicolumn{3}{|l|}{ Variables } & No CIN (92) & CIN (12) & Total & P. value \\
\hline \multirow[t]{2}{*}{ Gender } & Female & Number $(\%)$ & $20(21.7)$ & $6(50.0)$ & $26(25.0)$ & \multirow[t]{2}{*}{0.033} \\
\hline & Male & Number $(\%)$ & $72(78.3)$ & $6(50.0)$ & $78(75.0)$ & \\
\hline \multicolumn{2}{|l|}{ Age } & Mean $\pm \mathrm{SD}^{*}$ & $58.89 \pm 9.53$ & $62.5 \pm 12.44$ & - & 0.237 \\
\hline \multicolumn{2}{|c|}{ Baseline Creatinine Level } & Mean \pm SD & $0.85 \pm 0.19$ & $0.91 \pm 0.41$ & - & 0.658 \\
\hline \multirow[t]{2}{*}{ HTN $^{* *}$} & No HTN & Number $(\%)$ & $41(44.6)$ & $2(16.7)$ & $43(41.3)$ & \multirow[t]{2}{*}{0.065} \\
\hline & HTN & Number $(\%)$ & $51(55.4)$ & $10(83.3)$ & $61(58.7)$ & \\
\hline \multirow[t]{2}{*}{ DM**** } & No DM & Number $(\%)$ & $55(59.8)$ & $8(66.7)$ & $63(60.6)$ & \multirow[t]{2}{*}{0.646} \\
\hline & $\mathrm{DM}$ & Number (\%) & $37(40.2)$ & $4(33.3)$ & $41(39.4)$ & \\
\hline History of Nephrotoxic drugs & Negative & Number $(\%)$ & $80(87.0)$ & $8(66.7)$ & $88(84.6)$ & 0.067 \\
\hline
\end{tabular}

\section{Volume 6 Issue 6, June 2017 www.ijsr.net}


International Journal of Science and Research (IJSR)

ISSN (Online): 2319-7064

Index Copernicus Value (2015): 78.96 | Impact Factor (2015): 6.391

\begin{tabular}{|c|c|c|c|c|c|c|}
\hline & Positive & Number (\%) & $12(13.0)$ & $4(33.3)$ & $16(15.4)$ & \\
\hline \multirow{2}{*}{$\begin{array}{l}\text { Functional stage of kidney } \\
\left(\mathrm{eGFR}^{\infty} / \mathrm{ml} / \mathrm{min} / 1.73 \mathrm{~m}^{2}\right)\end{array}$} & Stage $1>60$ & Number $(\%)$ & $86(93.5)$ & $8(66.7)$ & $94(90.4)$ & \multirow[t]{2}{*}{0.003} \\
\hline & Stage 2, $60-30$ & Number (\%) & $6(6.5)$ & $49(33.3)$ & $10(9.6)$ & \\
\hline \multirow[t]{2}{*}{ Procedure } & PCI & Number (\%) & $44(47.8)$ & $0(0.0)$ & $44(42.3)$ & \multirow[t]{2}{*}{$0.001^{\mathrm{a}}$} \\
\hline & $\mathrm{CA}$ & Number (\%) & $48(52.2)$ & $12(100)$ & $60(57.7)$ & \\
\hline \multirow[t]{6}{*}{ Volume of contrast } & 50.00 & Number $(\%)$ & $32(34.8)$ & $4(33.3)$ & $36(34.6)$ & \multirow[t]{6}{*}{0.011} \\
\hline & 100.00 & Number $(\%)$ & $18(19.6 \%)$ & $8(66.7)$ & $26(25.0)$ & \\
\hline & 150.00 & Number (\%) & $7(7.6)$ & $0(0.0)$ & $7(6.7)$ & \\
\hline & 200.00 & Number (\%) & 17 (18.5) & & 17 (16.3) & \\
\hline & 250.00 & Number $(\%)$ & $12(13.0)$ & $0(0.0)$ & $12(11.5)$ & \\
\hline & 300.00 & Number (\%) & $6(6.5)$ & $0(0.0)$ & $6(5.8)$ & \\
\hline
\end{tabular}

${ }^{\infty}$ Estimated Glomerular Filtration Rate

Table 5: Cross tabulation of different risk factors versus contrast induced nephropathy (CIN) using $25 \%$ change criteria.

\begin{tabular}{|c|c|c|c|c|c|c|}
\hline \multicolumn{3}{|c|}{ Variables } & No CIN (72) & CIN (30) & Total & P value \\
\hline \multirow[t]{2}{*}{ Gender } & Female & Number $(\%)$ & $16(21.6)$ & $10(33.3)$ & $26(25.0)$ & \multirow[t]{2}{*}{0.211} \\
\hline & Male & Number $(\%)$ & $58(78.4)$ & $20(66.7)$ & $78(75.0)$ & \\
\hline \multicolumn{2}{|l|}{ Age (years) } & Mean $\pm \mathrm{SD}^{*}$ & $58.22 \pm 9.74$ & $62 . \pm 9.96$ & - & 0.077 \\
\hline \multicolumn{2}{|c|}{ Creatinine baseline (mg/dL) } & Mean \pm SD & $0.89 \pm 0.19$ & $0.78 \pm 0.28$ & - & 0.03 \\
\hline \multirow{2}{*}{$\begin{array}{l}\text { Hypertension } \\
\text { (HTN) }\end{array}$} & No HTN & Number $(\%)$ & $35(47.3)$ & $8(26.7)$ & $43(41.3)$ & \multirow[t]{2}{*}{0.053} \\
\hline & HTN & Number $(\%)$ & $39(52.7)$ & $22(73.3)$ & $61(58.7)$ & \\
\hline \multirow[t]{2}{*}{ Diabetes mellitus (DM) } & No DM & Number $(\%)$ & $45(60.8)$ & $18(60.0)$ & $63(60.6)$ & \multirow[t]{2}{*}{0.939} \\
\hline & $\mathrm{DM}$ & Number $(\%)$ & $29(39.2)$ & $12(40.0)$ & $41(39.4)$ & \\
\hline \multirow[t]{2}{*}{ History of Nephrotoxic drugs } & Negative & Number $(\%)$ & $66(89.2)$ & $22(73.3)$ & $88(84.6)$ & \multirow[t]{2}{*}{0.042} \\
\hline & Positive & Number $(\%)$ & $8(10.8)$ & $8(26.7)$ & $16(15.4)$ & \\
\hline \multirow{2}{*}{$\begin{array}{c}\text { Functional stage of kidney } \\
\left(\mathrm{eGFR}^{\infty} / \mathrm{ml} / \mathrm{min} / \mathbf{1 . 7 3 \mathrm { m } ^ { 2 } )}\right.\end{array}$} & Stage $1>60$ & Number $(\%)$ & $68(91.9)$ & $26(86.7)$ & $94(90.4)$ & \multirow[t]{2}{*}{0.413} \\
\hline & Stage $2(60-30)$ & Number $(\%)$ & $6(8.1)$ & $4(13.3)$ & $10(9.6)$ & \\
\hline \multirow[t]{2}{*}{ Anemia } & Negative & Number $(\%)$ & $71(95.9)$ & $28(93.3)$ & $99(95.2)$ & $0.625^{\mathrm{a}} \mathrm{OR}(1,69)$ \\
\hline & Positive & Number $(\%)$ & $3(4.1)$ & $2(6.7)$ & $5(4.8)$ & \\
\hline \multirow[t]{2}{*}{ Procedure } & $\mathrm{PCI}^{\S \S}$ & Number $(\%)$ & $34(45.9)$ & $10(33.3)$ & $44(42.3)$ & \multirow[t]{2}{*}{0.238} \\
\hline & $\mathrm{CA}^{\S}$ & Number (\%) & $40(54.1)$ & $20(66.7)$ & $60(57.7)$ & \\
\hline \multirow[t]{6}{*}{ Volume of contrast/ cc } & 50.00 & Number $(\%)$ & $30(83.3)$ & $6(16.7)$ & $36(34.6)$ & \multirow{6}{*}{$<0.001$} \\
\hline & 100.00 & Number (\%) & $10(38.5)$ & $16(61.5)$ & $26(25.0)$ & \\
\hline & 150.00 & Number (\%) & $7(100.0)$ & $0(0.0)$ & $7(6.7)$ & \\
\hline & 200.00 & Number $(\%)$ & $16(94.1)$ & $1(5.9)$ & $17(16.3)$ & \\
\hline & 250.00 & Number $(\%)$ & $9(75.0)$ & $3(25.0)$ & $12(11.5)$ & \\
\hline & 300.00 & Number $(\%)$ & $2(33.3)$ & $4(66.7)$ & $6(5.8)$ & \\
\hline
\end{tabular}

* Standard deviation, ${ }^{a}$ Fisher exact test, ${ }^{\infty}$ Estimated Glomerular Filtration Rate, ${ }^{\S \S}$ Percutaneous coronary intervention, ${ }^{\S}$

Coronary angiography

A univariate binary regression analysis of CIN of different variables using $0.5 \mathrm{mg} / \mathrm{dl}$ increase from baseline criteria shows that hypertension, functional stage of kidney and history of using nephrotoxic drugs, were the risk factors to predict increase in CIN (7.17 folds for functional stage) while decrease in risk for (male gender by 0.278 folds, and volume of contrast by 0.989 folds). History of using nephrotoxic drugs increases risk by 3 folds as shown in table 6.
Table 6: Univariate binary regression analysis of CIN using different variables

\begin{tabular}{|c|c|c|c|c|}
\hline \multirow{2}{*}{ Variables } & \multicolumn{2}{|c|}{$\begin{array}{c}\text { Using } 0.5 \mathrm{mg} / \mathrm{dl} \\
\text { increase from } \\
\text { baseline criteria. }\end{array}$} & \multicolumn{2}{c|}{$\begin{array}{c}\text { using } 25 \% \\
\text { increase from } \\
\text { baseline criteria }\end{array}$} \\
\cline { 2 - 5 } & OR $^{*}$ & P. value & OR & P. value \\
\hline Age & 1.039 & 0.229 & 1.041 & 0.08 \\
\hline Gender (male) & 0.278 & 0.042 & 0.552 & 0.215 \\
\hline Hypertension & 4.02 & 0.083 & 2.46 & 0.053 \\
\hline Diabetes mellitus & 0.743 & 0.647 & 1.034 & 0.939 \\
\hline $\begin{array}{c}\text { History of using } \\
\text { nephrotoxic drugs }\end{array}$ & 3.33 & 0.079 & 3 & 0.049 \\
\hline $\begin{array}{c}\text { Functional stage of } \\
\text { kidney }\end{array}$ & 7.17 & 0.008 & 1.744 & 0.417 \\
\hline Procedure & - & 0.997 & 1.7 & 0.241 \\
\hline Volume of contrast & 0.989 & 0.045 & 2.469 & 0.002 \\
\hline
\end{tabular}

*Odd ratio

Patients with hypertension, stage 2 of kidney function, history of using nephrotoxic drugs, and high volume of contrast showed a significant increase in serum creatinine from baseline compare to those how do not have such risk(s), as shown in table 7 . 


\section{International Journal of Science and Research (IJSR) \\ ISSN (Online): 2319-7064}

Index Copernicus Value (2015): 78.96 | Impact Factor (2015): 6.391

Table 7: Change of mean serum creatinine from baseline to the end of study according to each risk factor.

\begin{tabular}{|c|c|c|c|c|c|c|}
\hline \multirow{2}{*}{\multicolumn{2}{|c|}{ Risk factor }} & \multirow{3}{*}{$\begin{array}{c}\text { Number } \\
63 \\
\end{array}$} & \multicolumn{3}{|c|}{ Creatinine $(\mathrm{mg} / \mathrm{dL}) \pm S D^{*}$} & \multirow[t]{2}{*}{ P. value } \\
\hline & & & Baseline & End of study & Mean Change & \\
\hline \multirow[t]{2}{*}{$\mathbf{D M}^{* *}$} & No DM & & $0.9 \pm 0.26$ & $1.06 \pm 0.36$ & 0.16 & \multirow[t]{2}{*}{0.719} \\
\hline & $\mathrm{DM}$ & 41 & $0.8 \pm 0.16$ & $0.98 \pm 0.18$ & 0.18 & \\
\hline \multirow[t]{2}{*}{ HTN $^{* * * *}$} & No HTN & 43 & $0.84 \pm 0.17$ & $0.94 \pm 0.24$ & 0.10 & \multirow[t]{2}{*}{0.009} \\
\hline & HTN & 61 & $0.87 \pm 0.26$ & $1.07 \pm 0.33$ & 0.20 & \\
\hline \multirow{2}{*}{$\begin{array}{c}\text { Stage of renal function } \\
\left(\mathrm{eGFR}^{\$ \$} / \mathrm{ml} / \mathrm{min} / 1.73 \mathrm{~m}^{2}\right)\end{array}$} & Stage $1>60$ & 94 & $0.81 \pm 0.17$ & $0.96 \pm 0.21$ & 0.15 & \multirow[t]{2}{*}{0.001} \\
\hline & Stage $2(60-30)$ & 10 & $1.33 \pm 0.12$ & $1.67 \pm 0.25$ & 0.34 & \\
\hline \multirow[t]{2}{*}{ History of Nephrotoxic drugs } & Negative & 88 & $0.84 \pm 0.22$ & $0.99 \pm 0.27$ & 0.15 & \multirow[t]{2}{*}{0.015} \\
\hline & Positive & 15 & $0.98 \pm 0.28$ & $1.24 \pm 0.37$ & 0.26 & \\
\hline \multirow[t]{2}{*}{ Procedure } & $\mathrm{PCI}^{\infty}$ & 44 & $0.82 \pm 0.21$ & $0.95 \pm 0.27$ & 0.13 & \multirow[t]{2}{*}{0.066} \\
\hline & $\mathrm{CA}^{\S}$ & 60 & $0.89 \pm 0.24$ & $1.08 \pm 0.31$ & 0.19 & \\
\hline \multirow[t]{6}{*}{ Volume of contrast } & $50 \mathrm{cc}$ & 36 & $0.94 \pm 0.2$ & $1.09 \pm 0.29$ & 0.15 & \multirow[t]{6}{*}{0.003} \\
\hline & $100 \mathrm{cc}$ & 26 & $0.80 \pm 0.26$ & $1.07 \pm 0.34$ & 0.27 & \\
\hline & $150 \mathrm{cc}$ & 7 & $0.81 \pm 0.26$ & $0.87 \pm 0.32$ & 0.06 & \\
\hline & $200 \mathrm{cc}$ & 17 & $0.87 \pm 0.27$ & $0.97 \pm 0.34$ & 0.10 & \\
\hline & $250 \mathrm{cc}$ & 12 & $0.79 \pm 0.14$ & $0.91 \pm 0.15$ & 0.12 & \\
\hline & $300 \mathrm{cc}$ & 6 & $0.77 \pm 0.14$ & $1.03 \pm 0.19$ & 0.26 & \\
\hline
\end{tabular}

* Standard deviation, ${ }^{* *}$ Diabetes mellitus, ${ }^{* * *}$ Hypertension, ${ }^{\infty}$ Percutaneous coronary intervention,

${ }^{\S}$ Coronary angiography, ${ }^{\S \S}$ Estimated Glomerular Filtration Rate

\section{Discussion and Conclusions}

\section{CIN incidence}

Among all procedures utilizing $\mathrm{CM}$ for diagnostic or therapeutic purposes, CA and PCI are associated with the highest rates of CIN. ${ }^{(23)}$ In this study, the incidence of CIN related to angiography or angioplasty was estimated at $28.8 \%$ based on a $25 \%$ relative increase in serum creatinine criteria, $11.5 \%$ resulted from a definition of a $0.5 \mathrm{mg} / \mathrm{dL}$ absolute increase in serum creatinine.

In an Iranian study published in 2016, Khatami et al ${ }^{(24)}$, compared the prevalence of CIN in patients with normal S. $\mathrm{Cr}$ according to different diagnostic definitions. They found that the lowest prevalence of CIN $(3.8 \%)$ based on a 0.5 $\mathrm{mg} / \mathrm{dL}$ absolute increase in $\mathrm{S}$. Cr, the highest incidence of CIN was $30.5 \%$ based on a $25 \%$ relative increase in S. Cr. Serum creatinine is not an optimal indicator of renal function as the level is affected by many factors, including hydration status, diet and medications ${ }^{(25)}$. Therefore, the relative increase in serum creatinine may not reflect the true prevalence of CIN in patients with normal serum creatinine.

Kiyokuni et al ${ }^{(26)}$ assessed the three definitions of CIN and showed that a $0.5 \mathrm{mg} / \mathrm{dL}$ increase in $\mathrm{S}$. $\mathrm{Cr}$ is the best predictor of the long-term outcome in these patients.

According to Harjai et al ${ }^{(27)}$, both definitions that relative $25 \%$ and absolute $0.5 \mathrm{mg} / \mathrm{dL}$ increase of $\mathrm{S}$. Cr in patients with CIN are the most valuable predictors of major cardiovascular events in six months. Others have demonstrated that a $0.5 \mathrm{mg} / \mathrm{dL}$ increase in $\mathrm{S}$. Cr. is the better predictor of both short-term and long-term outcomes compared with a $25 \%$ relative increase in serum creatinine (28). In this study, we found that the rate of CIN in patient without risk factors was $20 \%$, while in those with risk factors was $31.6 \%$. Gruberg et al., stated that CIN occurred in $1.2 \%$ of the patients without risk factors, in $11.2 \%$ with one risk factor, and in $42 \%$ of the patients with two or more risk factors. (29)

\section{Risk factors of CIN}

As previously mentioned, underlying risk factors affecting renal failure following cardiac procedures are frequently related to the patient's condition, contrast media use, and even technical and procedural factors. In this study, we found that the rate of risk factors in CIN developed patients was $86.7 \%$ which is significantly high. In the study by Shoukat $S$ ${ }^{(30)}$, the variables with which the risk for CIN after PCI was assessed were hypertension, intra-aortic balloon pump use, congestive heart failure, a S. Cr level $>1.5 \mathrm{mg} / \mathrm{dl}$, age $>75$ years, anemia, diabetes mellitus, and CM volume.

\section{Regarding Ag:}

In this study, there was no significant effect of age on rate of CIN ( $p$ value was 0.08). Berns et al found that $50 \%$ of patient with age > 60 year developed CIN. ${ }^{(31)}$ This difference may be due to small sample size in this study.

\section{Regarding Gender}

In this study, we found that male gender was associated with lower risk of CIN ( $P$ value was $0.04 \& O R$ was 0.278 ). A Kuwaiti study ${ }^{(32)}$ showed that females were independently at higher risk of CIN by univariate analysis while male gender was found to be at a higher risk of CIN in another study. ${ }^{(33)}$

\section{Regarding Volume of Contrast}

In this study, we found that there is a significant relationship between volume of contrast \& CIN ( $P$ value was $0.002, O R$ was 2.4) with CIN incidence of $16.7 \%$ in dose of $50 \mathrm{ml} \&$ $66.7 \%$ in $300 \mathrm{ml}$ dose. Patients who underwent CA receive $50-100 \mathrm{ml} \&$ patients with PCI receive $150-300 \mathrm{ml}$.

An Egyptian study published in $2015^{(34)}$ found that the volume of $\mathrm{CM}$ was significantly associated with CIN. Solomon et al. ${ }^{(35)}$ reported that a higher volume of $\mathrm{CM}$ is associated with a higher risk of CIN. 


\section{International Journal of Science and Research (IJSR) \\ ISSN (Online): 2319-7064 \\ Index Copernicus Value (2015): 78.96 Impact Factor (2015): 6.391}

\section{Regarding Pre-Existing Renal Impairment}

In this study, we found that functional stage of kidney significantly affects CIN ( $p$ value was 0.008 , OR was 7.17) which was consistent with most previous results.

A Kuwaiti study published in $2009^{(30)}$ found that a preexisting renal impairment was the most important risk factor for CIN confirming our results. This is probably due to a decreased vasodilatory response and a slower clearance of contrast media compared to normal subjects. Abdel Ghani A. et al ${ }^{(32)}$, showed that the incidence of CIN was more than doubled in those with $\mathrm{S}$. Cr above $1.3 \mathrm{mg} / \mathrm{dl}$.

\section{Regarding Hypertension}

In this study, history of hypertension was emerged as determinants of CIN following angiography or angioplasty $(P$ value was 0.009) where there was a significant increase in $\mathrm{S}$. $\mathrm{Cr}$ from baseline (mean change).

An Iranian study published in $2013^{(36)}$ found that there is a transient acute renal dysfunction occurred in $12.8 \%$ of patients within $48 \mathrm{~h}$ after angiography or subsequent angioplasty and could be predicted by a myocardial infarction before the procedure or by a prior history of systolic hypertension.

\section{Regarding Diabetes Mellitus}

In this study, we found that the effect of DM as a risk factor seems to be a little or absent ( $p$ value was 0.93 ), this is true relatively when we compare incidence of CIN in diabetic \& non-diabetic patients, i.e. not because that CIN didn't occur in diabetic patients, but this is a false negative result. As the real results say that the incidence of CIN was high in both diabetics \& non-diabetics with some difference of percentage, this might be due to presence of other risk factors in non-diabetic patient which increased risk of CIN development, other cause might be inappropriate preprocedural preparation for those patients which increase the incidence of CIN. However, we found that the change in mean creatinine from baseline was more in diabetic patients. In a study done by Rihal et al. ${ }^{(37)}$, the incidence of CIN was found to be $2 \%$ in patients without diabetes and $3.7 \%$ in patients with diabetes with a baseline creatinine concentration of $1.1 \mathrm{mg} / \mathrm{dl}$ or less.

\section{Regarding Nephrotoxic Drug Use}

In this study, we found that the risk of CIN increased with history of nephrotoxic drugs usage (NSAIDs) by 3 folds ( $P$ value was 0.049 , OR was 3 ). Studies have shown that NSAIDs increase risk for renal injury, and this risk is dose dependent, related to drug half-life, and similar between cyclo-oxygenase-2 selective and nonselective agents ${ }^{(19)}$. Thus, concurrent use of these agents may increase risk of CIN.

\section{Regarding Anemia}

In this study, there was no relationship between anemia and CIN incidence ( $p$ value was 0.62 ). The relationship between low hematocrit levels and CIN has been investigated by Nikolsky et al. ${ }^{(18)}$ in a prospective study of 6,773 patients who underwent PCI. A lower baseline hematocrit was an independent predictor of CIN. Dangas et al. ${ }^{(9)}$ showed that the baseline hematocrit level is an independent predictor of CIN in patients with chronic kidney disease. This difference may be due to small sample size in this study, also patients in this study were well prepared and small number of them were anemic.

This study showed that transient acute renal dysfunction occurred in $28.8 \%$ of the patients within $48 \mathrm{~h}$ after angiography or subsequent angioplasty. It is precipitated by previously impaired kidney function, a prior history of systolic hypertension, and history of nephrotoxic drugs usage. There was a significant relationship between the volume of contrast media and the risk of CIN following angiography or angioplasty \& the risk was proportionately increase with the volume of contrast media. A simple risk score for CIN can be utilized to predict the probability of CIN after PCI and therefore more vigilance in applying preventive measures.

\section{Future Scope}

The steadily increasing use of contrast agents in radiological and interventional cardiac procedures has led to more research and studies of prophylactic strategies for its leading life-threatening side effect of (CIN). The importance of understanding of CIN, identifying patients at risk, attempting to minimize risk, and using preventative strategies, lies in the fact that no available treatment can reverse or ameliorate it once it develops, but prevention is possible.

In this study, it occurs more frequently in patients with underlying renal dysfunction, hypertension, nephrotoxic drugs usage. These risk factors are synergistic in their ability to predispose to the development of CIN. A careful riskbenefit analysis must always be performed prior to the administration of CM to patients at risk for CIN.

\section{References}

[1] Hou SH, Bushinsky DA, Wish JB, Cohen JJ, Harrington JT. Hospital acquired renal insufficiency: a prospective study. Am J Med. 1983;74(2):243-8.

[2] Christensen C. X-ray contrast media-an overview. Toxicology 2005; 209: 185-7.

[3] Mitchell AM, Jones AE, Tumlin JA, Kline JA. Incidence of contrast induced nephropathy after contrast-enhanced computed tomography in the outpatient setting. Clin $\mathbf{J}$ Am Soc Nephrol. 2010; 5(1): 4-9.

[4] Karlsberg RP, Dohad SY, Sheng R. Contrast-induced acute kidney injury (CI-AKI) following intra-arterial administration of iodinated contrast media. J Nephrol. 2010; 23(6): 658-66.

[5] Chuang FR, Chen TC, Wang IK, et al. Comparison of iodixanol and iohexol in patients undergoing intravenous pyelography: a prospective controlled study. Ren Fail. 2009; 31(3): 181-8.

[6] Solomon R, Dumouchel W. Contrast media and nephropathy: findings from systematic analysis and Food and Drug Administration reports of adverse effects. Investigative radiology. 2006; 41(8): 651-60. 


\section{International Journal of Science and Research (IJSR) \\ ISSN (Online): 2319-7064}

Index Copernicus Value (2015): 78.96 | Impact Factor (2015): 6.391

[7] Goldenberg I, Matezky S. Nephropathy induced by contrast media: Pathogenesis, Risk factors and Preventive strategies. Can Med Assoc J. 2005; 172: 1461-71.

[8] Radovanovic D, Urban P, Simon R, et al. Outcome of patients with acute coronary syndrome in hospitals of different sizes. A report from the AMIS Plus Registry. Swiss Med Wkly. 2010; 140(21-22): 314-22.

[9] Dangas G, Iakovou I, Nikolsky E, et al. Contrastinduced nephropathy after percutaneous coronary interventions in relation to chronic kidney disease and hemodynamic variables. Am J Cardiol. 2005; 95(1): 139.

[10]Devarajan P. Neutrophil gelatinase-associated lipocalin (NGAL): anew marker of kidney disease. Scand J Clin Lab Invest Suppl. 2008; 241: 89-94.

[11] Wong GTC, Irwin MG. Contrast-induced nephropathy. Br J Anaesth. 2007; 99: 474- 83.

[12]Detrenis, S, Meschi, M. del Mar Jordana Sanchez M, Savazzi G. Contrast medium-induced nephropathy in urological practice. J Urol. 2007; 178: 1164-1170.

[13] Thomsen HS. Nephrotoxicity. In: Thomsen HS, Muller RN, Mattrey RF. Trends in Contrast media. New York; Springer 1999;104.

[14] Ueda J, Nygren A, Hansell P, et al. Effect of intravenous contrast media on proximal and distal tubular hydrostatic pressure in the rat kidney. ActaRadiol. 1993; 34: 83-7.

[15] Persson, P.B., Hansell, P., and Liss, P. Pathophysiology of contrast medium-induced nephropathy. Kidney Int. 2005; 68: 14-22.

[16] Tumlin J, Stacul F, Adam A, et al. Pathophysiology of contrast-induced nephropathy. Am J Cardiol. 2006; 98(6A): $14 \mathrm{~K}-20 \mathrm{~K}$.

[17] Mehran R, Ayming ED, Nikolsky E, et al. A simple risk score for prediction of contrast induced nephropathy after percutaneous coronary intervention: Development and initial validation. J Am CollCardiol. 2004; 44: 1393 9.

[18] Nikolsky E, Mehran R, Lasic Z, et al. Low hematocrit predicts contrast-induced nephropathy after percutaneous coronary interventions. Kidney Int. 2005; 67: 706-13.

[19] James PA, Oparil S, Carter BL, et al. 2014 evidencebased guideline for the management of high blood pressure in adults: report from the panel members appointed to the Eighth Joint National Committee (JNC 8). JAMA. doi:10.1001/JAMA .2013.284427.

[20] American Diabetes Association. Standards of medical care in diabetes. Diabetes Care 2011; 34(1): S11-S61.

[21]KDIGO Clinical Practice Guideline for Anemia in Chronic Kidney Disease. 2012; 2 (4) ttp://www.kidneyinternational.org.

[22] Levey AS, Coresh J, Greene T, et al. Using standardized serum creatinine values in the modification of diet in renal disease study equation for estimating glomerular filtration rate. Ann Intern Med. 2006;145(4):247-54.

[23] Nash K, Hafeez A, Hou S. Hospital-acquired renal insufficiency. Am J Kidney Dis. 2002; 39: 930-936.

[24] Khatami MR, Nikravan N, Salari-Far M, et al, Contrastinduced nephropathy in patients with normal serum creatinine. Saudi J Kidney Dis Transpl. 2016; 27(1): 94100

[25] Jabara R, Gadesam RR, Pendyala LK, et al. Impact of the definition utilized on the rate of contrast-induced nephropathy in percutaneous coronary intervention. Am J Cardiol 2009; 103: 1657-62.

[26] Kiyokuni M, Kosuge M, Endo T, et al. Comparison of prognostic values of contemporary contrast-induced nephropathy definitions in patients with acute myocardial infarction undergoing emergency coronary angiography. Circulation 2011; 124: A8816.

[27] Harjai KJ, Raizada A, Shenoy C, et al. A comparison of contemporary definitions of contrast nephropathy in patients undergoing percutaneous coronary intervention and a proposal for a novel nephropathy grading system. Am J Cardiol 2008; 101: 812-9.

[28] Budano C, Levis M, D'Amico M, et al. Impact of contrast-induced acute kidney injury definition on clinical outcomes. Am Heart J 2011; 161:963-71.

[29]L. Gruberg, G.S. Mintz, R. Mehran, et al. Acute renal failure requiring dialysis after percutaneous coronary interventions, CatheterCardiovascInterv. 2001; 52: 409416.

[30] Shoukat S, Gowani SA, Jafferani A, Dhakam SH. Contrast-induced nephropathy in patients undergoing percutaneous coronary intervention. Cardiol Res Pract 2010; 20:649164.

[31] Berns AS. Nephrotoxicity of contrast media. Kidney Int. 1989; 36(4): 730-40.

[32] Abdel Ghani A, Tohamy KY. Contrast induced nephropathy and coronary intervention. Saudi J Kidney Dis Transpl 2009; 20(2):240-245.

[33] Feldkamp T, et al. Nephrotoxicity of isoosmolar and low osmolar contrast media is equal in low risk patients. ClinNephrol. 2006; 66: 322-30.

[34] Shams-Eddin Taher H, et al. Predicting contrast induced nephropathy post coronary intervention, The Egyptian Heart Journal 2015; 67: 337-343.

[35] Solomon RJ, Mehran R, Natarajan MK, et al, Contrastinduced nephropathy and long-term adverse events: cause and effect? Clin J Am Soc Nephrol, 2009; 4: 1162-1169.

[36] Nough. Incidence and Main Determinants of ContrastInduced Nephropathy following Coronary Angiography or Subsequent Balloon Angioplasty,131Cardiorenal Med 2013; 3: 128-135.

[37] Rihal CS, Textor SC, Grill DE, et al. Incidence and prognostic importance of acute renal failure after percutaneous coronary intervention. Circulation 2002; 105: 2259-64. Access network using stratospheric platforms. He now with DDI Tokyo Pocket Telephone, Inc. 